$$
\begin{aligned}
& \text { العدد الثالث عشر / المجلد الأول }
\end{aligned}
$$

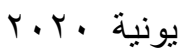

البحث رقم (v)

\title{
Using Technology To Enrich The Students Creative Expression
}

\author{
D / Walaa Ibrahim Kassem
}

Faculty Of Specific Education, Art Education Department

Alexandria University 


\section{Abstract:}

Technology plays a great role in contemporary arts, where it provides artists with another set of tools to express their creative vision and make it easily accessible to huge audience.

Trough teaching art at faculty of Specific Education, Art Education department the researcher has noticed that students attend painting and drawing courses which often required to work by using traditional mediums and techniques such as watercolor painting or oil painting, and teaching only with transitional mediums don't help to solve some problems, that undergraduate students faced while creating artworks.

The research addressed the digital technology which, supported artists to close the gap between the Idea and representation, and art educator can also use it as an approach for solving problems of art in teaching undergraduate's students, as well as a creative tool to develop students' skills and creative thinking, where creativity Included set of basic creative abilities according to the Torrance and Gulford of creative thinking Such as Fluency, Flexibility, Originality and Elaboration of Ideas.

\section{Introduction:}

Technology has become a tool for creative expression as well as a source for artistic information. In fact, much of yesterday's technology is today's fine art. Tow excellent examples of this are printmaking and photography. So the visual art and technology are mutually dependent upon one another.

Although science and art are separated one from another, but they are also directly related, we are living the era of science and digital technology, which has affected the creativity of the artist in various fields of arts, the computer is considered one of these modern and contemporary technology, that provided new horizons for creativity in the field of education, Therefore I believe that art educators at all levels must include digital technology as a part of the curriculum and not to stick only to classical techniques while teaching art, but also teach them how to use technology as a tool to create artistic imagery that effectively reflects and communicates their concerns and interests. 
The harmonious blending of art and technology is ever present in our everyday lives. We are surrounded by visual and material culture that takes full advantage of the highest quality forms of visual digital technology. As majority of youth are totally impressed in this kind of visual culture, so It's important to give digital art more space in curriculum in order to attract students who might think they have no artistic talent and consequently show little interest in visual art and the natural and appealing familiarization of students with the use of PCs, while at the same time opening up their artistic ways of expression (Kampouropoulou Maria, 2011, P.9 9). It's necessary to emphasis on the collaboration between digital technology and art, in order to develop creative thinking in undergraduate students by using computer as a way to produce innovative and distinctive artworks, and also use it to serve design ideas in art projects.

\section{The role of Technology in Contemporary Art:}

Technology plays a great role in contemporary arts, where it provides artists with another set of tools to express their creative vision and make it easily accessible to audience, Therefore art needs technology to grow and meets the promoted aesthetic tastes and needs increasingly grow up to realize the global society.

The use of technologies throughout history has always affected the way artists create their work. The photograph created an astounding impact on modern art as artists responded to photography and also implemented it as an artistic tool. Current technologies have similarly allowed artists to use new tools to produce their works with completely new artistic processes.

By exploring how technology has impacted the world of art, artists can gain a better understanding of how to create new forms and processes that elder artists have not yet considered. Michael Noll was one of the first researchers to use a digital computer to create artistic patterns and to formalize the use of random processes in the creation of visual arts and that making him one of the earliest digital computer artists. He proposed in the 1960s that the digital computer might become a creative artistic medium. (Martin Krampen \& Peter Seitz, 1967 p. 65-79). The cooperation between visual art and technology provided some artists with a means of manipulating existing imagery, they use technology as a part of their works, they might 
include images that show technological developments, mass produce posters, use many televisions all showing a different part of the same scene in an installation, use projectors to show images of people in a dark storefront, or use electronic signs to communicate messages.

A growing number of artists have a strong ambitious and aware of the new global contemporary art languages, Therefore they used new technology in their art works to introduce themselves as apart of this global world, as well as they defend their own social and cultural identity, In this way they present themselves as a new movement.

In fact, digital media contributed phenomenally in giving anew dimension to the institutions of art. The definition of art has changed immensely, gone are those days where an artist used to design his masterpieces on paper and took months to finally produce an artwork. No doubt, new media art often involves interaction between artist and observer or between observers and the artwork, which responds to them. Yet, as several theorists and curators have noted, such forms of interaction, social exchange, participation, and transformation do not distinguish new media art but rather serve as a common ground that has parallels in other strands of contemporary art practice.

The invention of the computer has been a boon to art and with the use of computer artists can create something that was not possible earlier. The way art has defined itself is changing with the introduction of computer in the recent phase. Digital art goes well with natural sciences too, it depends on the artist how he is observing, conceiving and projecting natural things and also his surroundings. An artist scientifically uses lines, shapes, colors, textures, forms, sizes and spaces to develop an artwork and computers help a greatly in this regard. (Archana Rani, 2018, p 64)

Computer technology is used by computer visual art to deal with images, that is to say operate and process images. The image is simply a flat, twodimensional art form. To integrate computer vision art into image processing, the first thing to understand is the structure layout, color ratio, and background of the image so that certain subjective intention can be added on the basis of understanding artistic conception and complete creation and processing of images. Through this "incorporated" art form, on the one hand, people's systematic understanding of images is enhanced, which can give 
them new artistic value according to their own emotions. On the other hand, it also promotes the development of image creation modes and improves traditional single form of artistic expression, thus fulfilling the diversified artistic needs of people in the current era, and accelerating the development of contemporary digital media art. (Yan Hou, 2018,P.1143)

Some of artists have been involved with computer technology to generate and manipulate with images, such as an American feminist artist "Barbara Kruger", much of her work engages the merging of found photographs from existing sources with pithy and aggressive text, that involves the viewer in the struggle for power and control that her captions speak to, she develops her ideas on a computer. The British feminist film theorist "Laura Mulvey" argues that Kruger adds text that cuts across the picture plane to found and enlarged photographs, creating messages that are sometimes (a silent cry of personal pain) and sometimes (a slogan of political anger). Figure 1. (Laura Mulvey. 2009. P.132).

"Debbie Rose Mayer", one of American artist and Professor at the Institute of Fort Lauderdale in Florida, she said "When I started drawing my paintings on a computer I've faced a lot of critics from artists and my academic colleagues about the credibility of this art and its importance in the intellectual movement of modern formative arts". Most of them detracted from the value of this work on both artistic and creative levels, particularly classic artists. To face such critics I took several years of attempts to convince them that digital art is considered the art of exceptional value and distinctive and that the computer as a artistic device represent specific addition in the field of artistic creativity. 


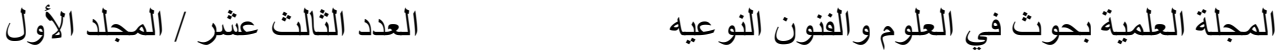

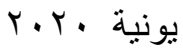

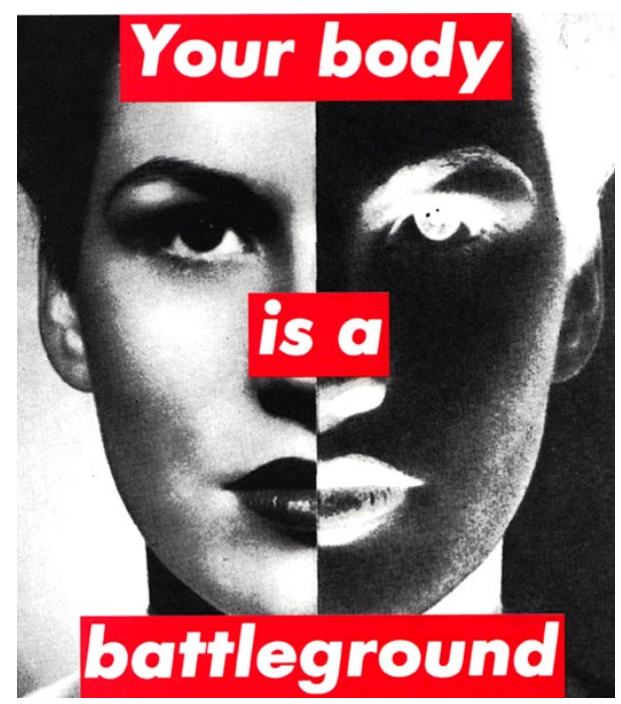

Figure 1: Barbara Kruger, Your Body is a Battleground, 1989 Photographic silkscreen

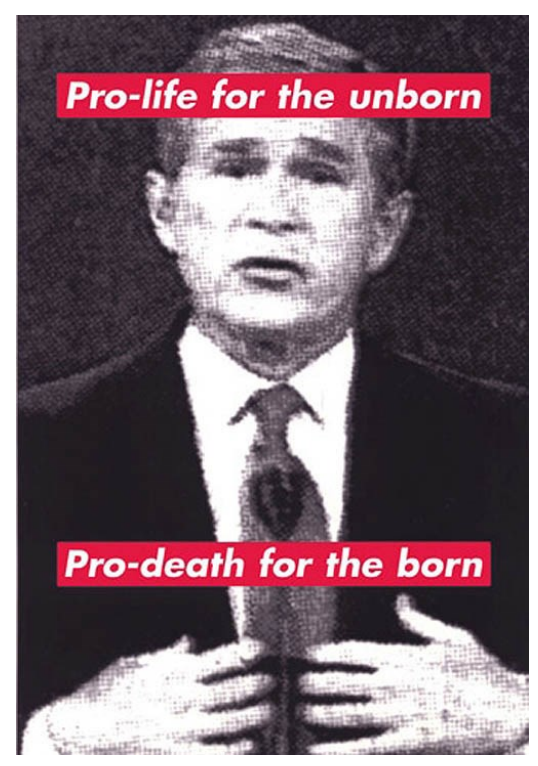

Figure 2: Barbara Kruger Pro-life for the unborn/ Pro-death for the born) 2004 
Using technology in art is a way for the developing the artwork and submits it in modern methods; however, the digital art cannot cancel the artist's efforts because the human mind drives the technology and not vice versa. On the other hand it achieves the artwork within short time and hidden all flaws and corrects its negative points, it is the responsibility of contemporary artists to control these new technologies in order to expand their potential to create new forms of art.

\section{Enrich the Creative Expression through Digital Technology:}

Each medium possesses has its own unique characteristics and qualities in application. Students are encouraged to experiment with a range of mediums that guided them to reach to the desired expression, they can also mix different media with computer technique for creative interpretation and communication of ideas. Students should thus be guided to think, understand and apply the qualities of the media in context to the objectives and effects desired rather than be solely trained on the technicalities of the media.

The medium need not sit in isolated purity. There is no law that forbids paint and photography from combining on a single surface. Quote from the British painter Richard Hamilton, "From my perspective there is no limits on subject matter or stylistic languages of expression, I see no virtue in circumscribing the technical means of realization. The image will always be more important than the rationale of its execution". (Halmilton Richard: 1997.p7).

We are already equipped with multiple art techniques, and art mediums, they are not limited as only watercolor, oil painting, or sketching with pencil, but surely they are more, where artists could use multiple methods, processes or means of expression to demonstrate confirm their points of views, as well as digital technology which, supported artists to close the gap between the Idea and representation, and art educator can also use it as an approach for solving problems of art in teaching undergraduate's students.

\section{Photography as a Creative Process in Creating a New Artwork:}

Since the mid nineteenth century, photography has truly become a fusion between science and the creative eye. As with any new electronic gadget of today, the first box cameras captured the curiosity of people who wanted to know what they were capable of producing. While the concept of 
photography was understood before the daguerreotype came into existence. Artists reacted to this new device with amazement and curiosity, while some artists refused to accept photography as an art form and protested that photography was a soulless. This technology could be used only as a tool to assist artists in drafting their artwork, although the capability of projecting an image was not new, in the nineteenth century the technology introduced by the camera obscura took an innovative direction. (Arnason and Kalb: 2003, p.15). The camera did not eliminate realistic painting, and technology will not eliminate the traditions of fine art. From the 1960s till today, photography considered one of trends in contemporary art.

The contemporary Iranian artist "Shirin Neshat", who used photos as a base of her art she used mixed media pieces of silver gelatin with ink sense and cover parts of the female face and body with abstract designs and Persian calligraphy. She chooses specific compositional audience. The selection of these four elements of Neshat's choice of photography as a way of expression are important so that they allow the artist to communicate with her audience in a manner which she thought agreeable to be as reproduction of "reality." Figure 3,4.

She said in one of her interview "I have found that the simplicity of the image is essential to give a sense of clarity within its very complex setting. To that effect, I use black and white photography, which also echoes the dichotomies I am interested in exploring and highlights the juxtapositions of the ideas I'm visualizing”. (Shadi Sheybani: 1999, Interview).

The Contemporary Egyptian Artist "Sabah Naim" is walking along streets with camera in hand, she observes that were people too busy to notice her. She found them with anonymous faces singled out in a sea of strangers. The more anonymous and obscure a subject, the greater her fascination. She discreetly steals these frames of life; sometimes caught by the subject Naim nevertheless walks away with what she wants in her camera, and she apply her works by using a variety of media and techniques, from drawing to stitching her canvases, she forms simple, often blanched sections that contrast softly with the monochrome print, Figure 5. (Shady El Sayed: 2007, p.267). Naim showed visually stunning photographic compositions of common Egyptian people approach to her work, which are instantly recognizable: the manipulation of photographs with various inputs of color, abstractions and her signature use of neatly folded newspaper. Naim introduces embroidery to 
her photographs, confirming her belief that medium should not be limiting to what she's attempting to portray, Figure 6.

Digital art and photography seem to be the reincarnation of what painting portrait was to original photography. In it lays a new sense of control and exact ability. Much more like the control of paint on canvas, but much less like the well-established medium, photography; even paint on canvas can be controlled digitally. Using common illustration software such as Corel Draw, Adobe illustrator, Adobe Photoshop, and many more, you can actually paint an entire oil painting using only an electronic pen hooked up to a pad. When things are like painting and photography seem to define the entire realm of the art industry, the idea of a Digital tool doing these things more efficiently.

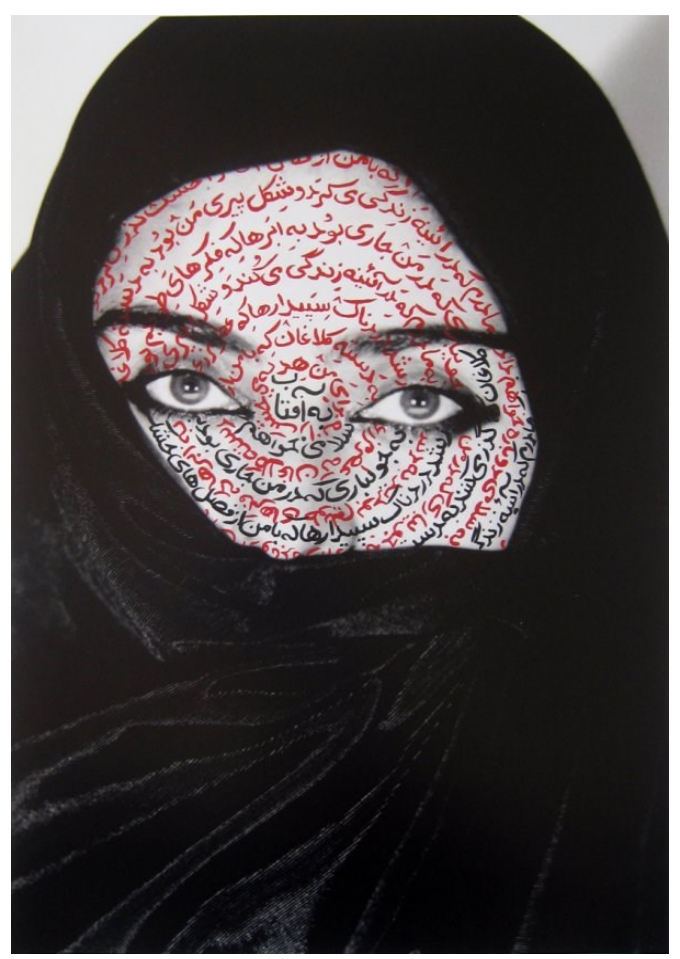

Figure 3: Shirin Neshat 'I am its Secret' 1993" The Museum of Contemporary Art, Los Angeles, Private Collection, New York 


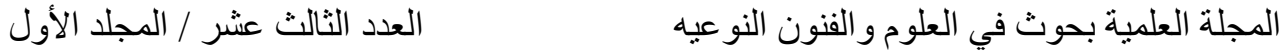

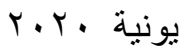

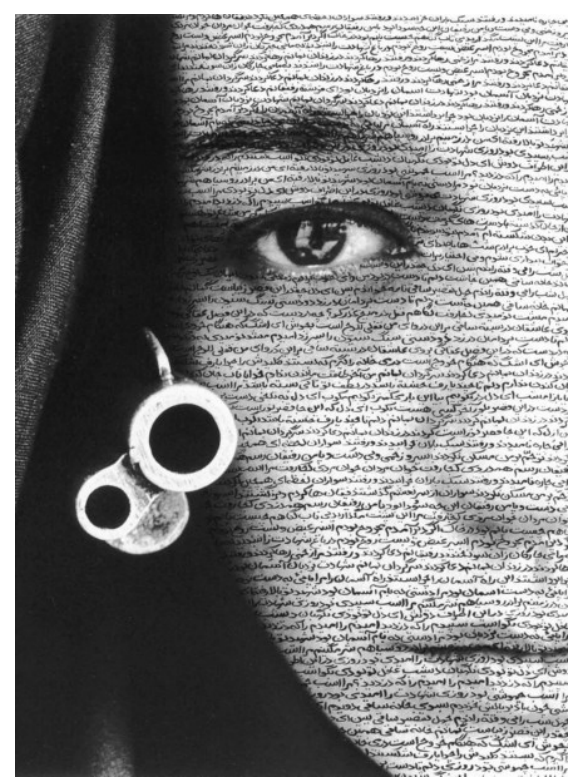

Figure 4: Shirin Neshat, Speechless, 1996 print and ink,

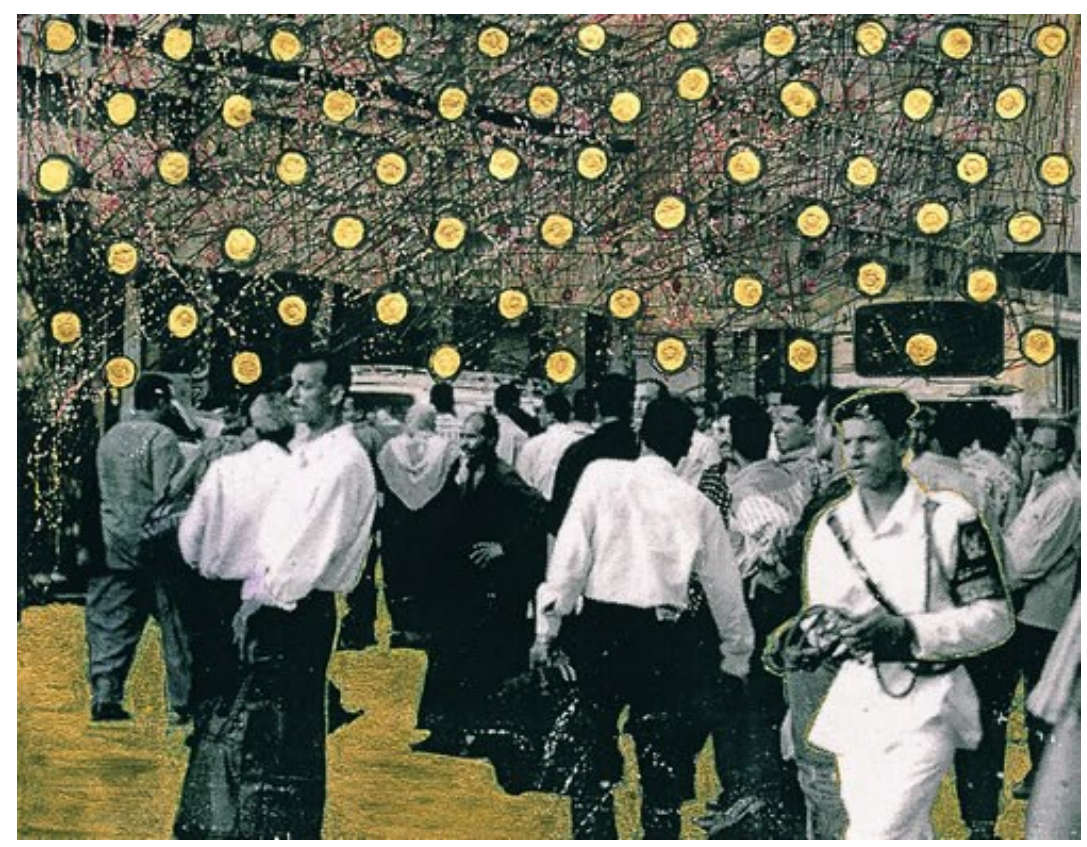

Figure 5: Sabah Naim, City People 2003 Mixed Media 140 x $135 \mathrm{~cm}$ 


$$
\begin{aligned}
& \text { العدد الثالث عشر / المجلد الأول } \\
& \text { المجلة العلمية بحوث في العلوم و الفنون النوعيه }
\end{aligned}
$$

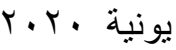

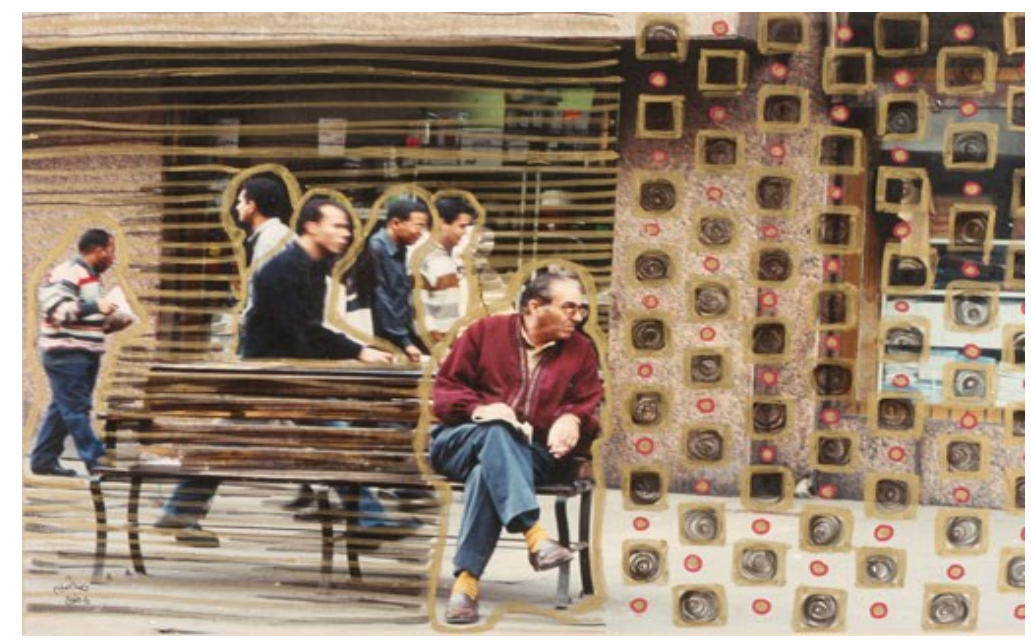

Figure 6: Sabah Naim, Cairo Street 2006, Mixed Media on paper

\section{Using Computer as a part of the creative process:}

Photography may not be final Project, but it may become part of a creative process. Computer enables to achieve innovation and distinctive artworks, and also it serves ideas in some creative projects. Software applications such as Photoshop allows the user to transform and manipulate photos and images by applying filters or taking parts of one picture and putting them into another in order to create a new form.

In fact, digital media contributed phenomenally in giving anew dimension to the institutions of art. The definition of art has changed immensely, gone are those days where an artist used to design his masterpieces on paper and took months to finally produce an artwork. No doubt, new media art often involves interaction between artist and observer or between observers and the artwork, which responds to them. Yet, as several theorists and curators have noted, such forms of interaction, social exchange, participation, and transformation do not distinguish new media art but rather serve as a common ground that has parallels in other strands of contemporary art practice. (Archana Rani, 2018, p 64)

Trends of technology have an impact on arts, and on the way we develop our creativity and imagination. With computer programs such as Adobe Photoshop, Adobe Illustrator, CorelDraw, INKscape and etc. allowed to some artists and graphic designers to explore new ways to envision and develop their work. These types of software applications help artists to bring 
new forms into existence. The computer acts as an assistance tool in the process of creativity and imagination, they are enormously differing from traditional techniques.

Advancements in technology and computer aided arts and allowed artists to explore new forms of artistic representation that placed a greater emphasis on the imaginative and aesthetic qualities of art. As for the steps followed by the artist "Debbie Rose Mayer" in creating her painting, she says " I usually start by collecting the largest possible number of photographs related to the subject and I do copies and scan them, after that I use Photoshop program to combine the proposed images of scanner, and put them in the right place on the screen in order to serve the idea of artwork. The number of used images in the same work may reach to about 26 to 28 images. Then I continue to move image on the screen until I find the suitable situation for each image in the painting as a whole. Sometimes I have to use digital light effects to deepen the idea and strengthening it. Figure 7.

I believe that the digital art has no limited process, on certain words, any student who has talent and knowledge of using computer programs, such as Photoshop to develop endless formations of artwork projects, which unify the artistic vision imaginative capacity with high-tech computer programs to achieve together exaggerations of artworks that were not being realized without this technology. I'm personally one of ardent to art of computer and I take time and effort needed to create paintings and visual formation to stimulate the human mind and develop the imagination. 


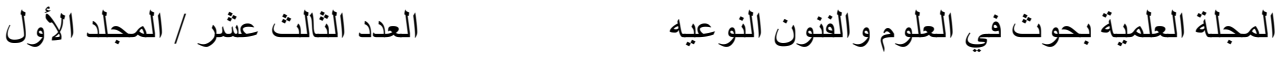

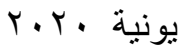

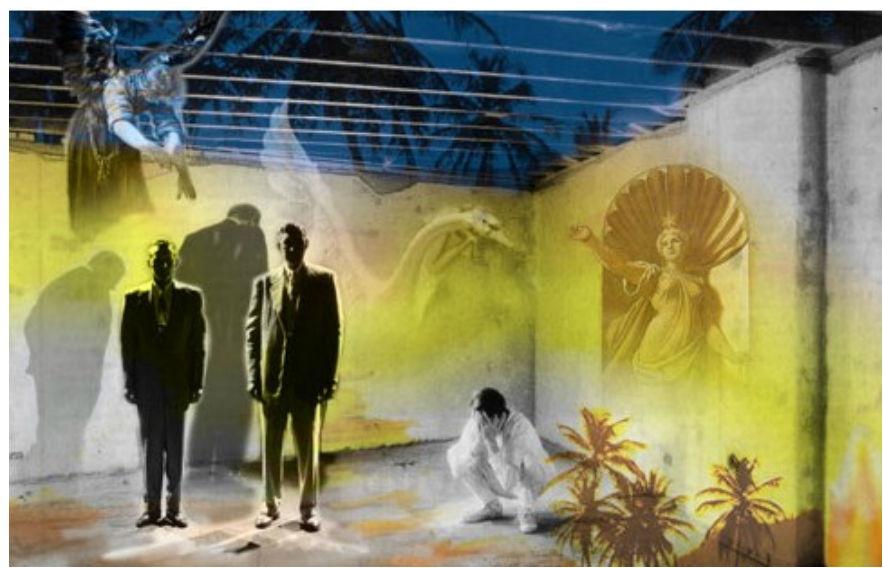

Figure 7: Debbie Rose Mayer, Judgment in the Garden, Graphic Design

\section{Enhancing Students' Artworks through Digital Technology:}

This research addressed the ability of students to get benefit from using technology in their artwork through workshops, which took place in 2011, it has continued for 3 months with undergraduate students Figure 8. The researcher has noticed that students at the Faculty of Specific Education, Alexandria University, attend painting and drawing courses which often required to work by using traditional mediums and techniques such as watercolor painting or oil painting, and teaching only with transitional mediums don't help to solve some problems, that undergraduate students faced while creating artworks, therefore I used digital technology as a creative tool to develop students' skills and creative thinking, where creativity Included set of basic creative abilities according to the Torrance and Gulford of creative thinking Such as Fluency, Flexibility, Originality and Elaboration of Ideas.

Laura $\mathrm{H}$. Chapman has been referred, that the practice is mainly aimed to understand the role of art as it means development the creative power to transform and use materials and tools into modes of art expression, so that the learner through the exercise of certain activities, which make artworks take the form of the physical.

She adds that the creative artwork as an area of humanitarian operations include thinking and feeling, perception, imagination and expression, and through the exercise of those operations, the learner is gaining visual language of the artwork, that helps him forming and formulation the artwork 
and gain the ability to innovate as well. (Dina Adel: 2001. P.113)

Students explore the influence of technology on artists as it applies to sources of inspiration the development of ideas or images and choice of tools to communicate visual art ideas. Digital image capture is the combination of many technologies as it is considered as an easy mix of photography and scanners for computer to allow students to add their images and drawings to the computer.

Computer could not produce or create ideas by itself; however it helps to reduce undergraduate student's effort for the production of art project. Software Application such as Photoshop presents many possibilities to help students of art to create their works in less time with satisfactory and innovative results. Computer becomes a different kind of the student tools; so as the student can create various forms and then they can repeat forms in different sizes and change colors. Students also can add and delete any image and motive without trouble.

\section{The Practical Framework:}

The current study identifies an approach based on combining of appliance with advantages of our heritage assaying to explore deeds and expression of cultural identity. In return, our relationship identification with tools of modern technology, that we use now in all aspects of life in order to know the truth and the reality such integration and contradictory coexistence, which can be the same as form of contemporary identity.

Each Student has performed a creative art work that explore the concept of assertion of culture identity, which was focused on places and neighborhood in Alexandria city, and to achieve that by using digital technology as an approach to enhance new means of art expression, such as digital cameras, computer, color printers and scanners to create digital images, and they used software applications like Photoshop CS to edit and create digital images with a creative insight that enabled undergraduate art students to generate innovative solutions and opportunities to apply them. There is no doubt that such capabilities should help students to develop their own skills and make them more able to gain new ideas which they easily promotes them.

This paper addressed the ability of undergraduate students enabling them 
from using technology in their works. I dealt with students who might think they have no artistic talent and consequently show little interest in visual art and who are lack in art expression or who face problems to achieve composition successfully, therefore students been divided into three groups according to problems they faced while creating their artworks:

\section{1st Group:}

The 1st group consists artworks, which has been used digital technology in order to help students to create artistic composition Art is a means of entertainment, who feel that their imagination and creativity are enhanced when they are engaged in Art projects and believe that they are interested in Art, it helps them to develop aesthetic standards. Students said that Technology makes Art more accessible to audience and that they know how to use a computer to change shapes and zoom in details by Photoshop program, which allows students to transform images by applying filters or taking parts of one picture and putting them into another. Figure (9), (10), (11), (12), (13)

\section{2nd Group:}

The 2nd group consists of students, who are facing problem not only with their imagination, but also with well-chosen color combinations at their artworks. In fact, there are colors that work so badly together that they could literally hurt the eyes when staring or would hinder from understanding images. On the other hand, well color combinations don't just help catch attention; but they help sustain interest also.

Photoshop one of the software programs, which aid to generate many color scheme in order to help uninspired students and to give them possibility of choosing colors easily and how to use in specific artworks and related to the tasks. After that students apply their works on papers or canvas by using acrylic color and add some changes to be more expressed to their ideas. Figure (14), (15), (16), (17).

\section{3rd Group:}

The 3rd group consists of students who used digital technology in order to help them to create new forms and artistic compositions. The computer here is not used to generate an end design, but it plays an essential role as a part of 


$$
\begin{aligned}
& \text { العدد الثالث عشر / المجلد الأول }
\end{aligned}
$$

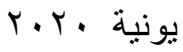

$$
\begin{aligned}
& \text { المجلة العلمية بحوث في العلوم و الفنون النو عيه }
\end{aligned}
$$

the creative process.

And the main aim in this group is to make mutual coexistence of modes of artistic production between traditional and technological ways.

Students are consumers with freedom to choose technological tools that complement rather than they can replace more traditional methods of artistic creation, and there is no perceived risk in their minds because they perceive technology as neutral at worst and positively enabling at best. Figure (18), (19), (20).
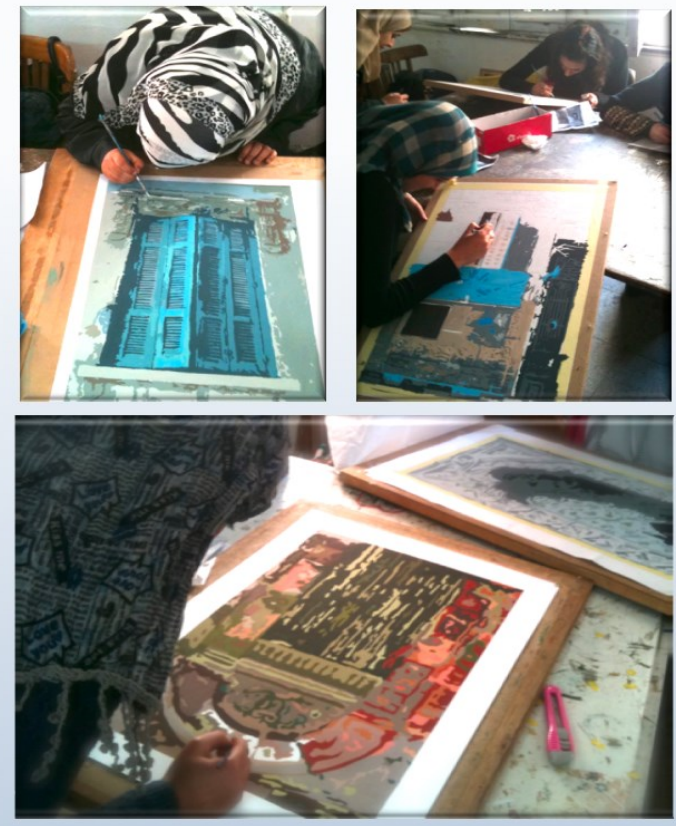


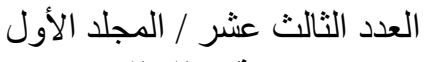

المجلة العلمية بحوث في العلوم و الفنون النو عيه

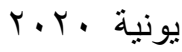

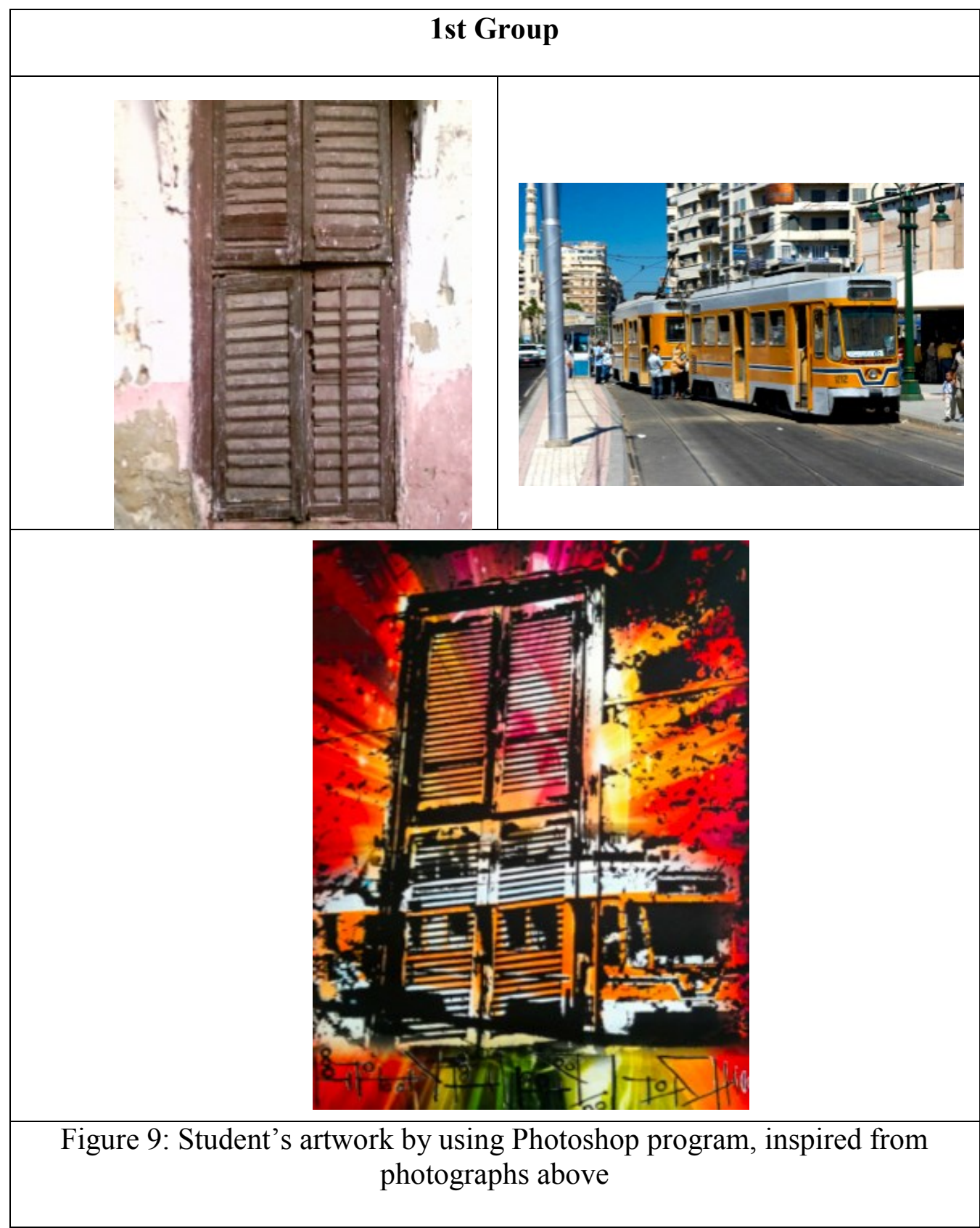


The Student used possibilities of Photoshop program in order to achieve successfully composition of artwork by using pictures photographic which took by digital camera for one of the old neighborhoods in Alexandria city. The student picked out pictures of the Tram and one of the worn windows from old building, she manipulated with those pictures by using Photoshop CS filters drawing effect, sizes, color and she added part of her old painting as background after emphasized on colors.

I have noticed that using photography and Photoshop Program helped her to create and promote her idea in less time with satisfactory and innovative results. 


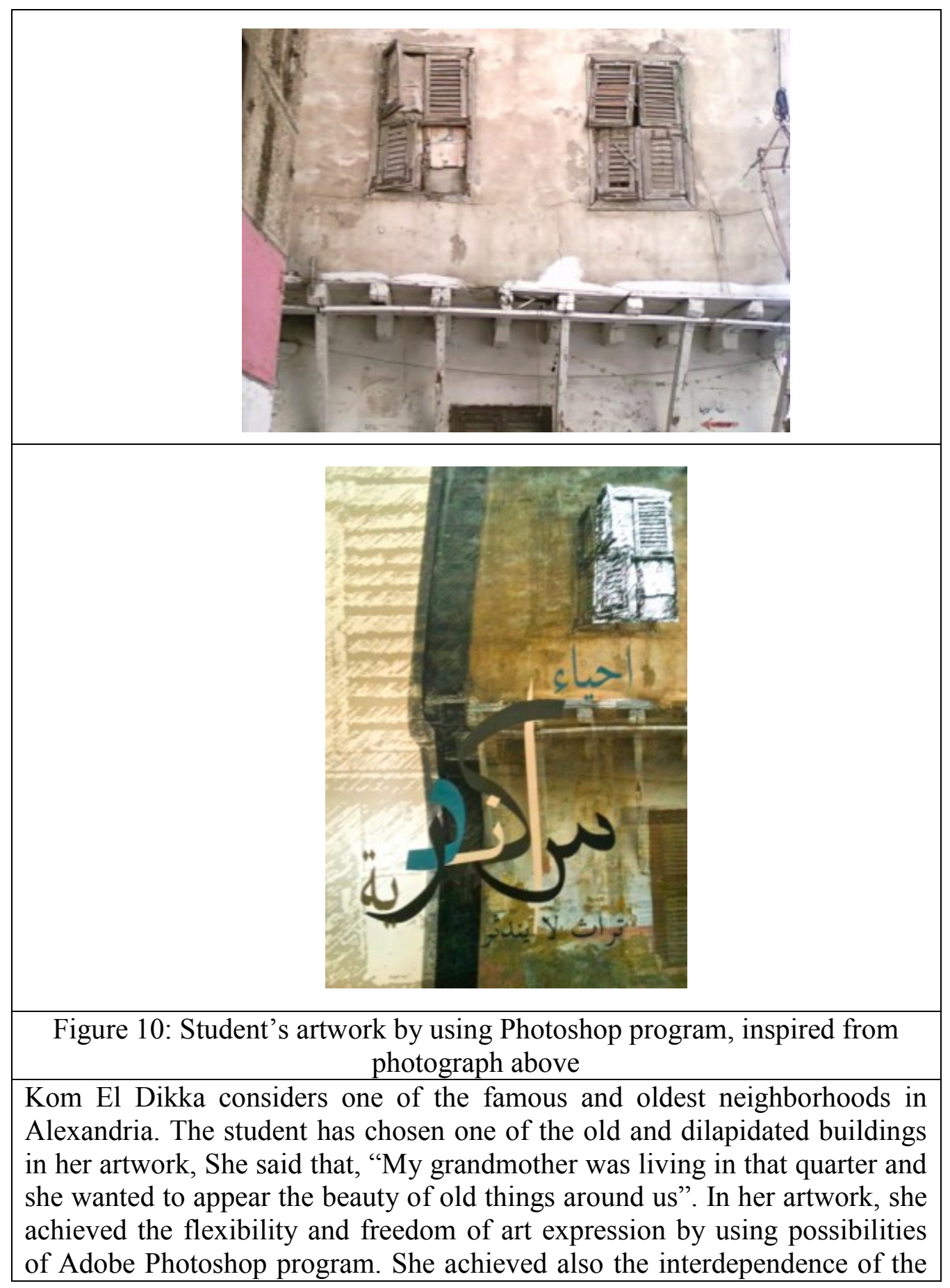




$$
\begin{aligned}
& \text { العدد الثالث عشر / المجلد الأول }
\end{aligned}
$$

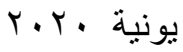

elements and forms in her artwork besides using Arabic calligraphy.

The utilization of photographs as an aid to Bring out the values of expressive in artwork, as it helped student to generate new ideas.

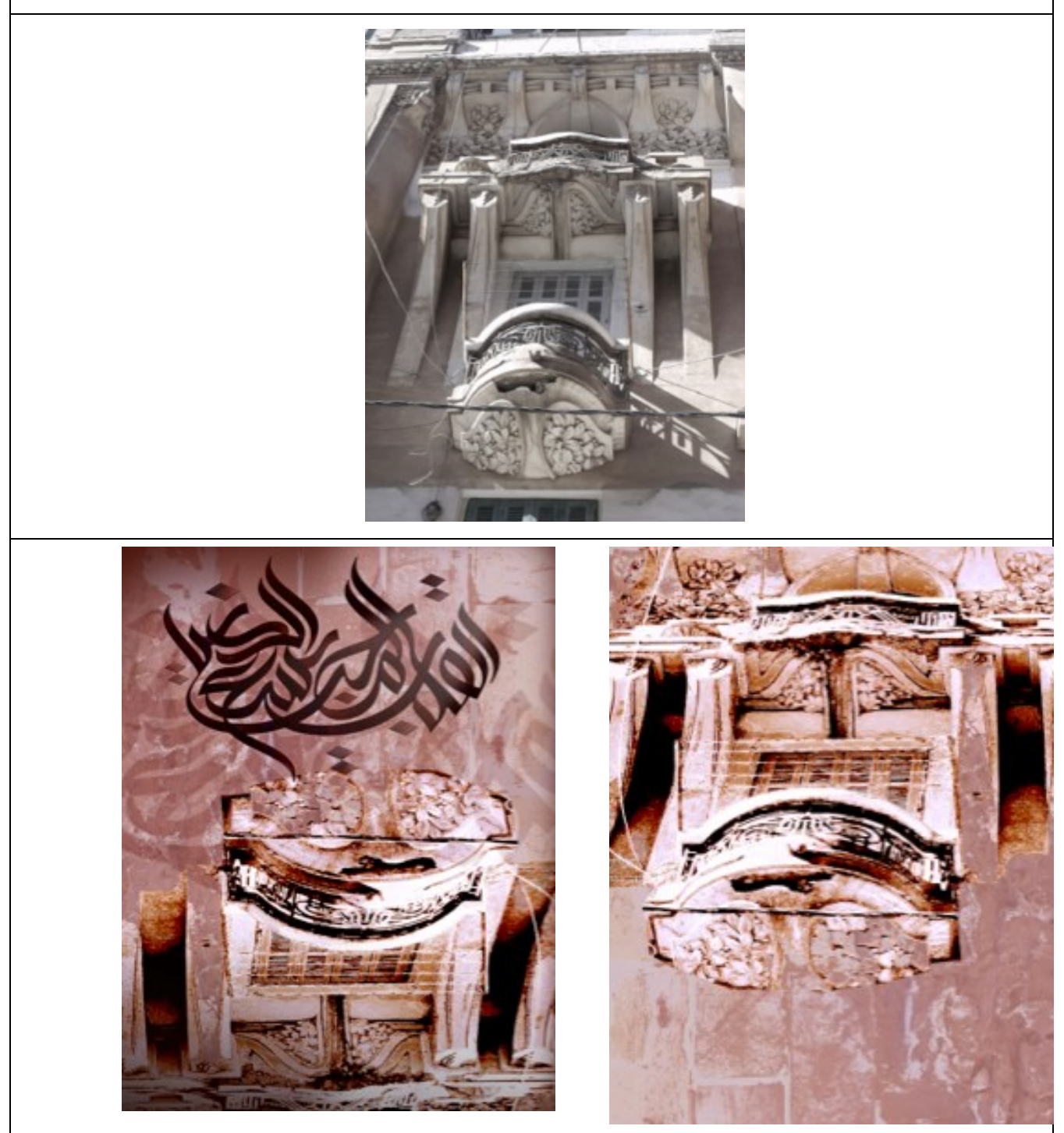

Figure 11: Student's artwork by using Photoshop program, inspired from photograph above 
Photoshop program allowed the fluency and freedom of expression and successful composition for artwork by using pictures photographic, which took for old building. The photograph has highlighted the values of the expressive in this work of art. The student used only brawn color and its degrees in order to give the impression of old heritage. She realized the balance in artwork in terms of putting the image of balcony in the middle; she exceeded the rules of Arabic calligraphy and made it as artistic element in order to make another composition with an aesthetic values.
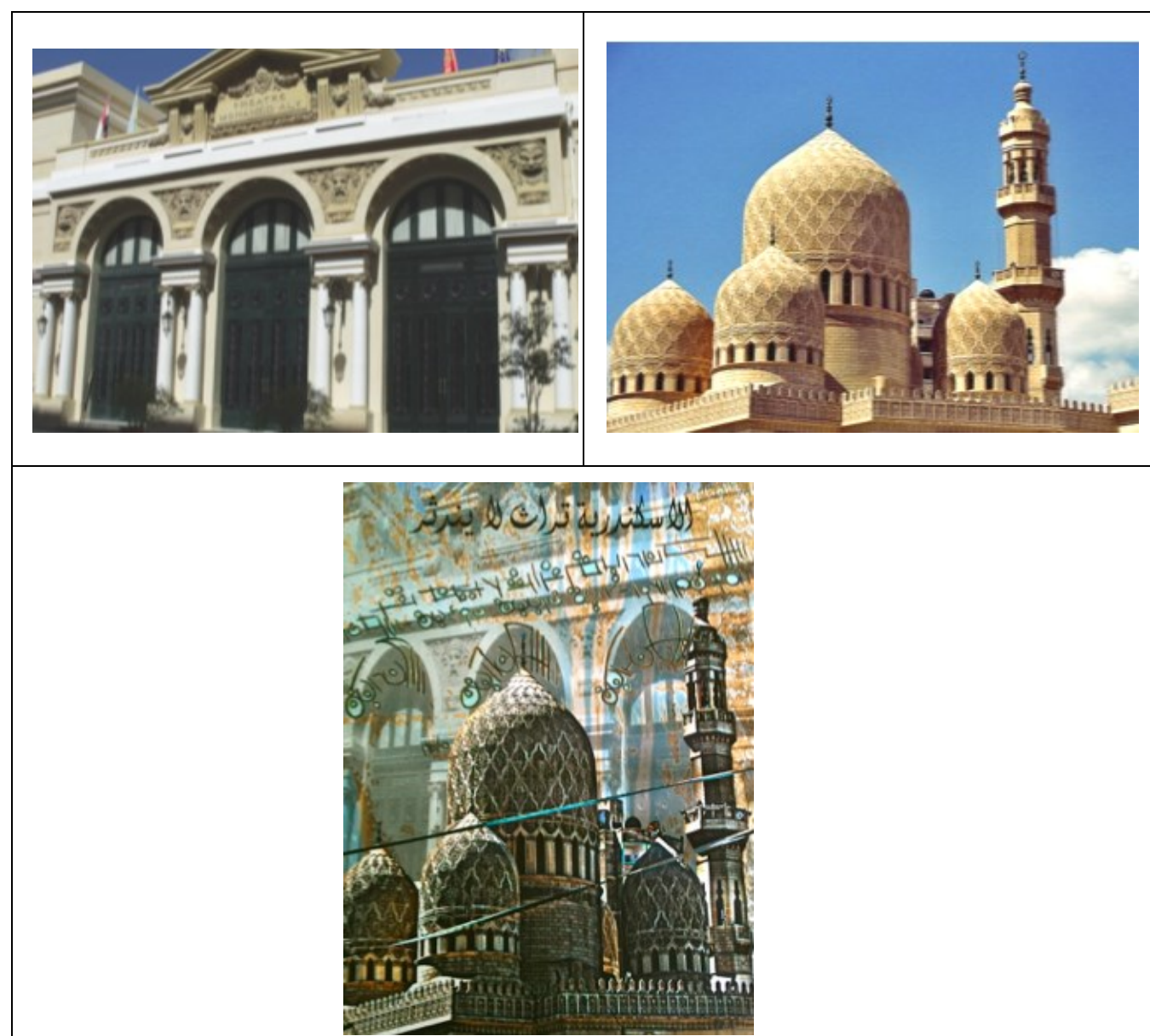

Figure 12: Student's artwork by using Photoshop program, inspired from photographs above 
El Mursi Abul Abbas Mosque was built primarily in 1775 over the tomb of a Spanish scholar and saint in Alexandria, and became over times the most famous mosques at Alexandria. Photographs in this artwork highlighted the values of the expressive work of art. The students achieved it by using Adobe Photoshop harmony between artistic elements to give aesthetic dimensions. Student has manipulated with another photo in the background, of Sayed Darwish Theatre in Alexandria that designed based on the architectural style of the Greek architect. In terms Alexandria replete with a diverse heritage, the student makes coexists between the oriental and Greek style architecture in order to emphasis on culture diversity in the city.

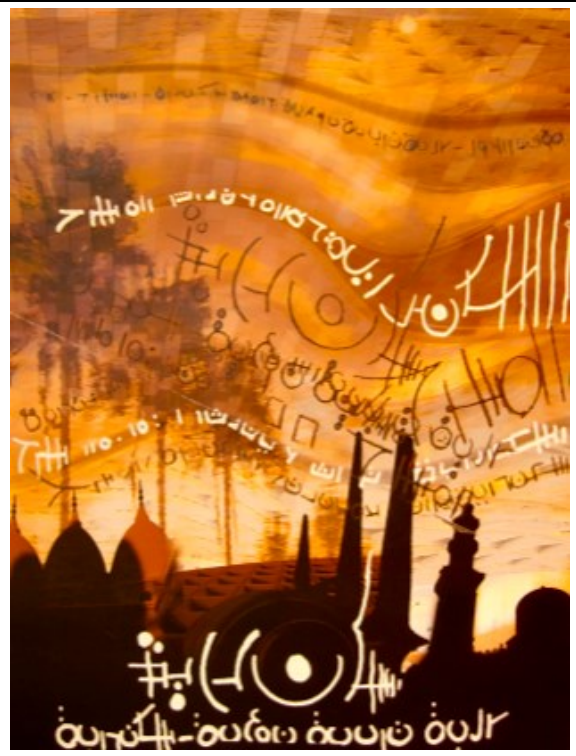

Figure 13: Student's artwork by using Photoshop program, inspired from his own photographs

In this artwork student collected photos of famous and remarkable historical sights in Alexandria city and put them together after using silhouette effect to emphasis the power of actuators shape. He exceeded the rules of Arabic calligraphy and made it as artistic form in order to make another composition, he emphasis on the contrast between the color of writing and the elements. The student realized the balance between the constituent elements of the artwork.

Using Adobe Photoshop contributed to deal with symbols and shapes with a flexibility and versatility. This artwork addresses the elements and forms in order to express cultural identity 


\begin{tabular}{l} 
2nd Group \\
\hline $\begin{array}{l}\text { Figure 14: Student's artwork by Acrylic after using Photoshop to generate } \\
\text { color scheme inspired from photographs above }\end{array}$ \\
possibilities of Adobe Photoshop program. She picked One of photos that \\
and she added Motifs. Students achieved successful composition for artwork \\
and colors. After several attempts she used cool colors tend more than warm \\
colors such as Blue, gray, silver in order to have a calming effect and to give \\
a sense of comforting and nurturing. After that she applied it on paper by \\
using Acrylic color.
\end{tabular}




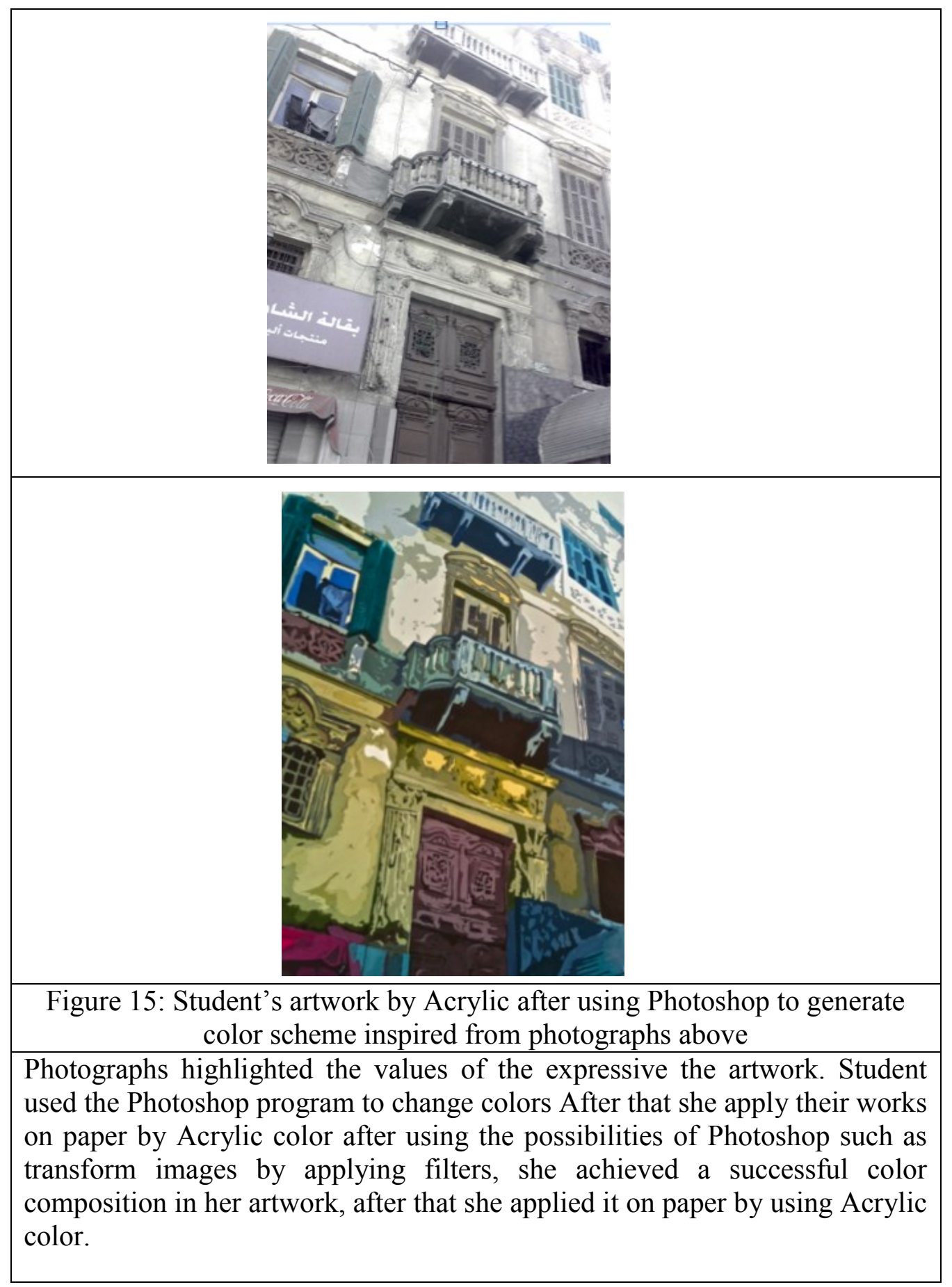




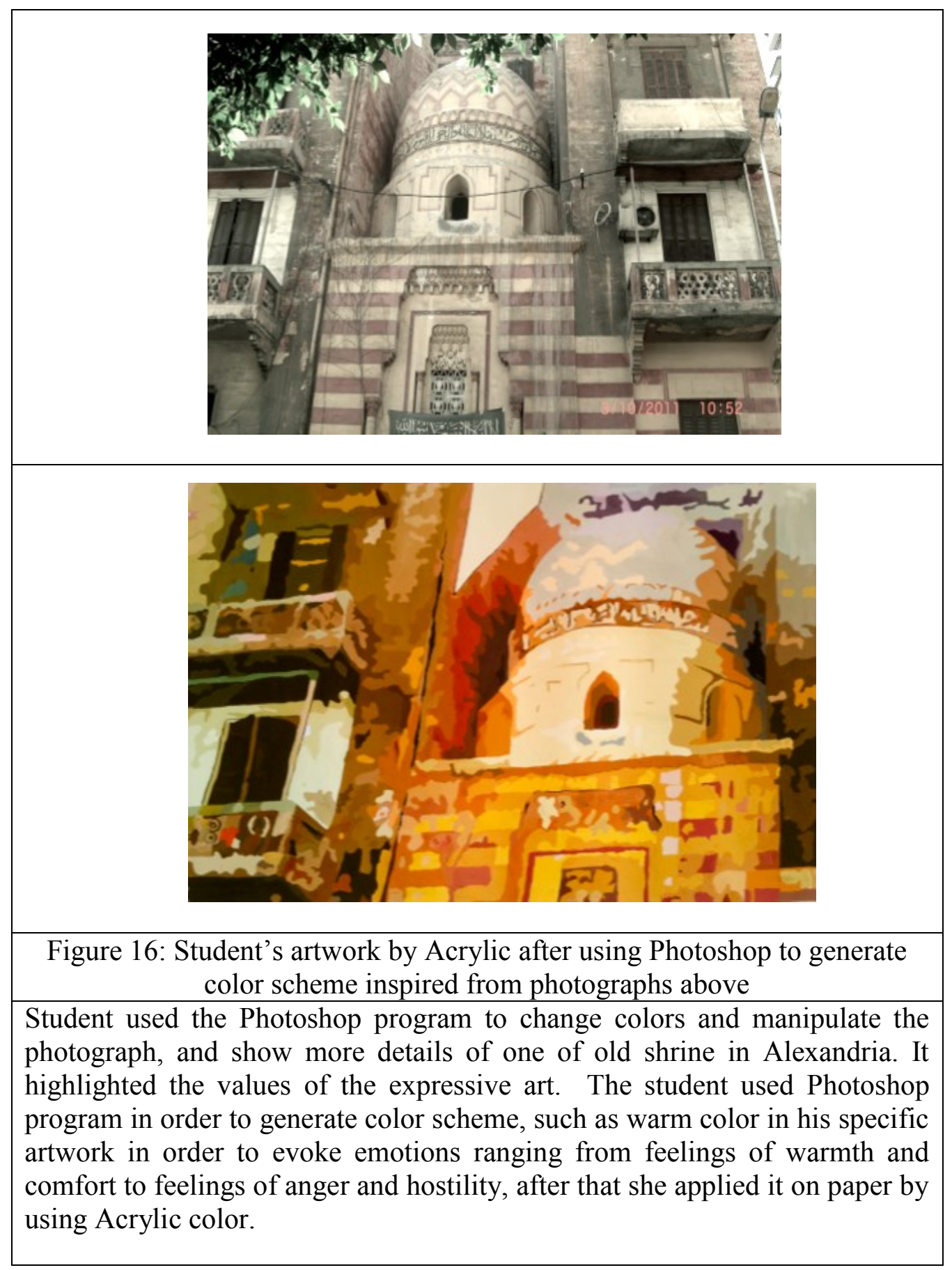




$$
\begin{aligned}
& \text { العدد الثالث عشر / المجلد الأول }
\end{aligned}
$$

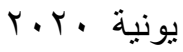

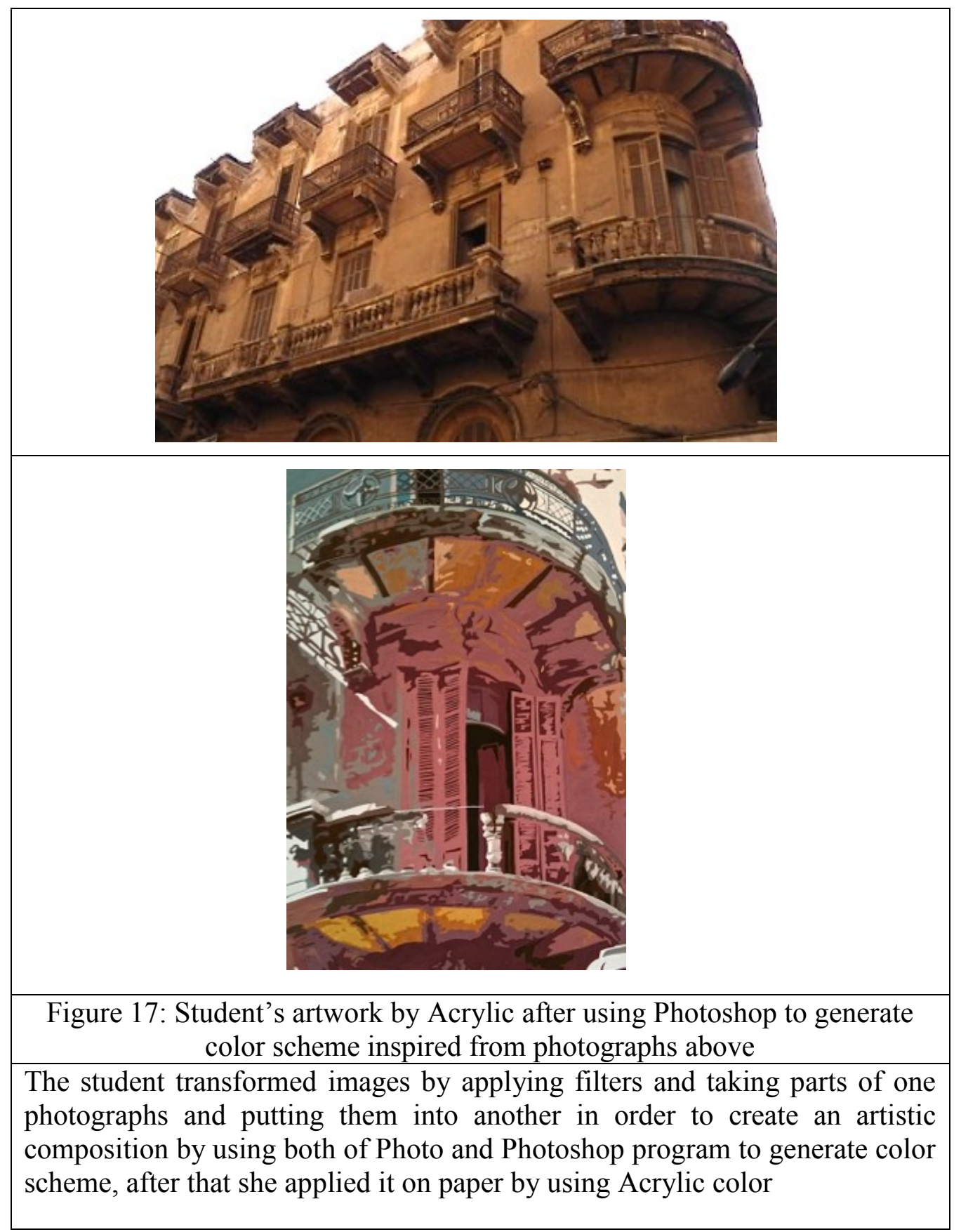




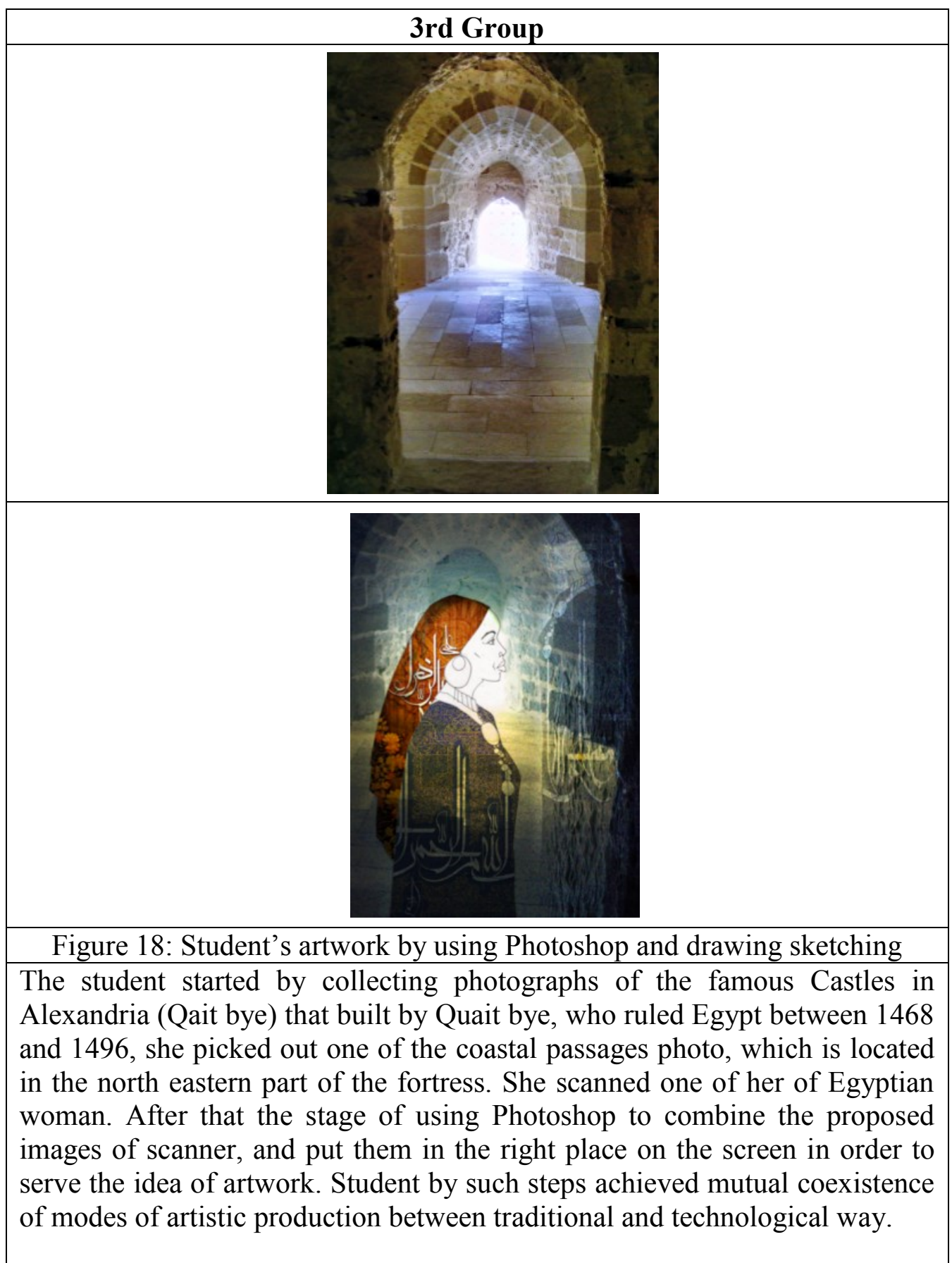




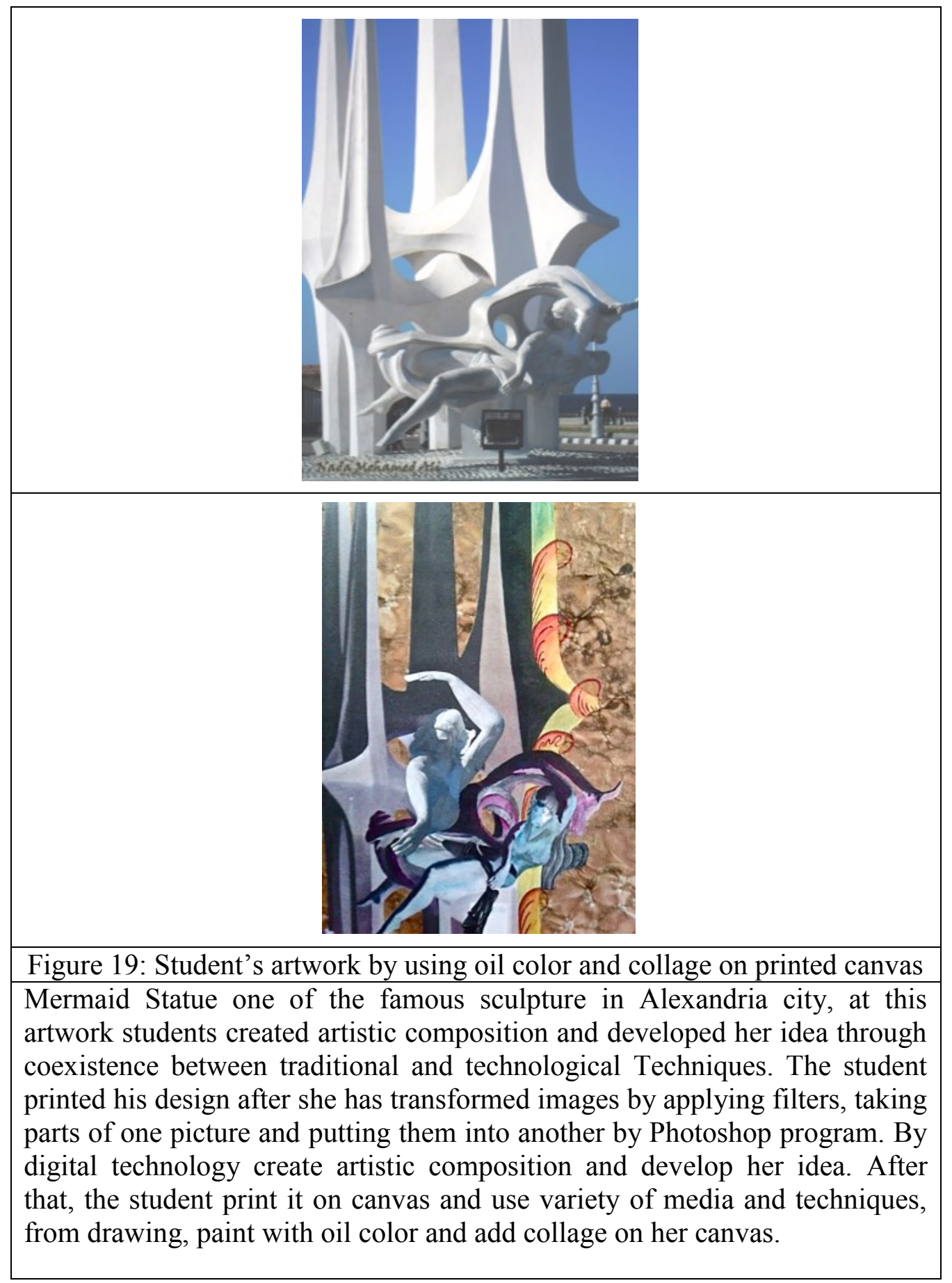



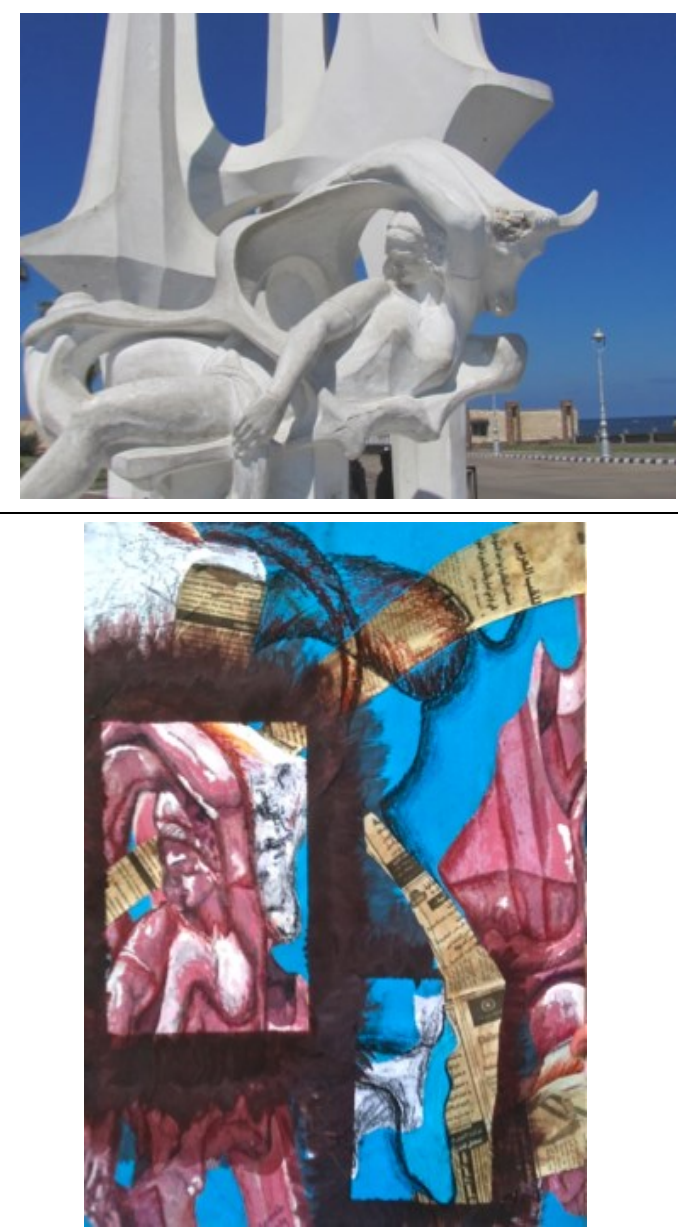

Figure 20: Student's artwork by using oil color and collage on printed canvas

The student inspired this composition from Mermaid Statue after using the possibilities of Photoshop such as images transformation by applying filters and taking parts of one picture and putting them into another. She added more details and other materials after printing it on canvas. She achieved the flexibility and freedom of art expression through mixing both of traditional and technological Techniques, photography and computer enhanced student's imagination and creativity. 


\section{Statistic and Analysis of the Results:}

The majority of Questionnaire's items have been based on Chapman 's steps for the exercise of the artwork, which includes the ability to form ideas, the ability to develop ideas, the ability to use art materials, respond to the visual elements, Analysis and interpretation and to judge the work of art.

After survey the satisfaction rate of arbitrators in field of art education came proportion high in all the items on the form, the following form illustrates this figure 21 .

- Percentage of satisfaction on student's artworks in 1st Group is $82 \%$, which refers that Technology helps students to form and develop ideas as well as enhanced imagination and creativity.

- Percentage of satisfaction on student's artworks in 2nd Group is $91 \%$, which means that Technology helped uninspired students to achieve successful combinations, color combinations and choose what colors to use in specific artworks related tasks.

- Percentage of satisfaction on student's artworks in 3rd Group is $87 \%$, which refers students able to create artistic composition and develop their ideas through coexistence between traditional and technological Techniques. 


\section{How Can Digital Technology Enhance New Means of} Expression

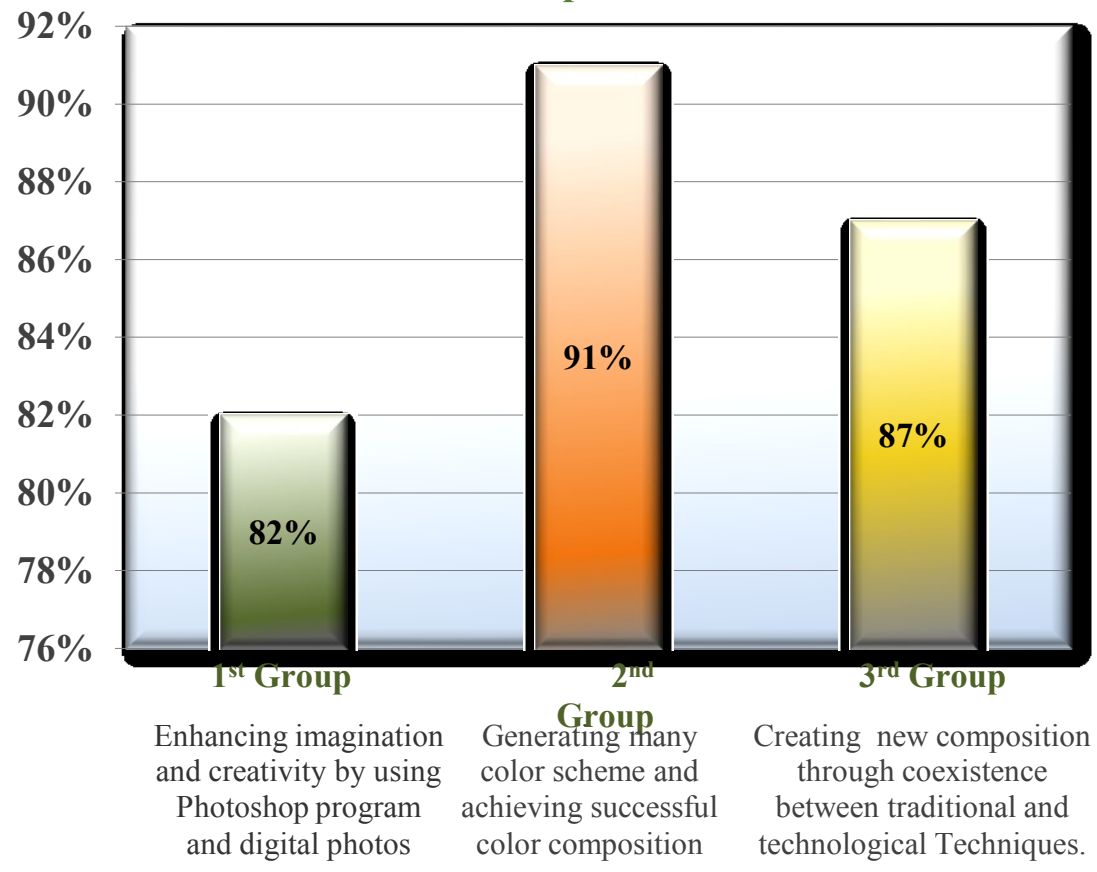

Figure 21: Satisfaction rate proportion of how can digital technology enhance new means of expression

\section{Conclusion:}

New Technology promotes the artistic character of multimedia applications, creates new types of Art, and supports boundaries between art and technological applications to be more indistinguishable. The use of digital Technologies in Art leads to the creation of new learning fields that motivate the students to be accurate and positive. Therefore instructors in art education field has to develop creative thinking in their students through using new technologies as a way to produce innovation and distinctive works of art. 
Artistic expression is an important aspect of Arts education. It refers to the evoked filling and ideas that are expressed through works of art. It not only gives an opportunity for students to express themselves artistically, but also it provides students with an opportunity to become aware of how artists both past and present have expressed themselves through their achievements. As well, Artistic expression involves the world we live in, and the ways in which art is used to express our values and believes of the society.

In the field of expressive art there are many of ways to express, and approaches in a different ways. Art is timeless and doesn't fade away with the latest trend. It has been proven through the ages that art are changing and technology will not eliminate the traditions of fine art.

\section{Results:}

- Digital technology presents many possibilities to help student of art to create their works in less time with satisfactory and innovative results.

- The role of technology in contemporary arts, where it provides artists with another set of tools to express their creative vision and make it easily accessible to huge audience.

- Using digital technology as a creative tool developed creative thinking of students and produce artworks, which characterized with Fluency, Flexibility, Originality and Elaboration of Ideas.

- Through coexistence between traditional and technological Techniques, students able to create artistic composition and develop their ideas.

- Technology proved that it enables to create many performances and responds to the arts. Each of these disciplines is special applicable communications skill that is so important to the workforce of today.

- Advancements in technology aided art education students to explore new forms of artistic representation that realized greatest emphasis on the imaginative and aesthetic qualities of art. 


\section{References:}

Archana Rani, 2018, Digital technology: it's Role in Art Creativity. Journal of Commerce and Trade, October 2018 Vol.8 No 2

Arnason, H. and Peter Kalb. (2003) History of Modern Art, 5th ed. Upper Saddle River, New Jersey: Prentice Hall print.

Cheryl M. Hamilton (1998) Chapter 6: Using Artistic Strategies, in Creating Meaning through Art: Teacher as Choice Maker, Judith Simpson et al. (Upper Saddle River, NJ: Merrill Prentice Hall).

Dina Adel Hassan (2001), The Effectiveness of a Suggested Program On Training Art Education Teachers in Secondary Schools to Use Teaching Strategies to Develop Creative Thinking, M.A. Degree in Art Education, faculty of Education-Alexandria University.

Kampouropoulou Maria (2011). Teaching Art Using Technology: Canadian Center of Science and Education.

Michael Noll (1967), The Digital Computer as a Creative Medium. IEEE Spectrum, Vol. 4 No. 10.

Pamela Harris Lawton (2007), Bridging the Traditional And Technological Aspects of Culture Through Art Education, the forum on public policy.

Pickover, Clifford A. (1992), Visions of the Future. New York: St. Martin's Press Print.

Yan Hou (2018), Applied Research of Computer Visual Arts on Digital Media in the Internet Age, Advances in Intelligent Systems Research, volume 147

International Conference on Network, Communication, Computer Engineering

Thurk, Jessica and Gary Alan (2003). The Problem of Tools: Technology and the Sharing of Knowledge" Acta Sociologicia. 
Martin Krampen and Peter Seitz (1967) Computers and the Visual Arts," Design and Planning 2: Computers in Design and Communication, Hastings House, Publishers, Inc.: New York.

Hamilton Richard, (1997). New Technology and Printmaking, Hansjorg Mayer,Alan Cristea Gallery.

Hegel, G.W.F. Aesthetics (1975). Lecture on Fine Art. London. Oxford,Press Print.

Laura Mulvey (2009). Visual and Other Pleasures (New York: Palgrave Macmillan.

Sarah Graham-Brown (1988). Images of Women: The Portrayal of Women in Photography of the Middle East, New York: Columbia University.

Shady El Sayed El Noshokaty (2007) Utilizing Media Arts in Consolidating the Artist's creative through to Express The culture Identity, $\mathrm{PhD}$ Thesis Presented to the Faculty of Art Education. 